\title{
Student and Faculty Outcomes of Undergraduate Science Research Projects by Geographically Dispersed Students
}

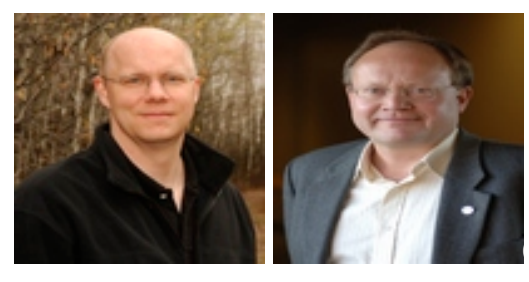

Lawton Shaw and Dietmar Kennepohl Athabasca University, Canada

\section{Abstract}

Senior undergraduate research projects are important components of most undergraduate science degrees. The delivery of such projects in a distance education format is challenging. Athabasca University (AU) science project courses allow distance education students to complete research project courses by working with research supervisors in their local area, coordinated at a distance by AU faculty. This paper presents demographics and course performance for 155 students over five years. Pass rates were similar to other distance education courses. Research students were surveyed by questionnaire, and external supervisors and AU faculty were interviewed, to examine the outcomes of these project courses for each group. Students reported high levels of satisfaction with the course, local supervisors, and faculty coordinators. Students also reported that the experience increased their interest in research, and the probability that they would pursue graduate or additional certification. Local supervisors and faculty affirmed that the purposes of project courses are to introduce the student to research, provide opportunity for students to use their cumulative knowledge, develop cognitive abilities, and independent thinking. The advantages and challenges associated with this course model are discussed.

Keywords: Distance education; undergraduate research; senior undergraduate project; science education; research supervisor; research mentor 


\section{Introduction}

Most educational jurisdictions require post-secondary institutions to have some sort of undergraduate research experience in the sciences ${ }^{1}$ to meet their program (and sometimes institutional) accreditation. While research has been present in many bachelor's degrees over the years, it is only relatively recently that it is being explicitly identified as an essential component and made mandatory. Indeed, major government initiated studies like the report from the Boyer Commission (1998) in the US clearly signaled 'integrating research and education' with a move to 'scholar-teachers' and 'research-based learning.' From the academic perspective, the benefits of undergraduate research in science are also well established and there is strong consensus in the literature that it is an effective vehicle for learning (Short, Healey, \& Romer, 2010; Seymour, Hunter, Laursen, \& DeAntoni, 2004; Bauer \& Bennett, 2003; Kardash, 2000). Furthermore, in the sciences the approach to learning is problem solving and scientific inquiry, and this forms the model for navigating and dealing with hypotheses, facts, laws, and theories (Kennepohl, 2013). It is therefore not surprising that the practical components (laboratories, field work, clinics) are at the heart of most science programs, or that more research activities are being introduced at the undergraduate level (Taraban \& Blanton, 2008).

The integration of research in an undergraduate program has many facets and is not trivial in its identification let alone its implementation. Healey (2005) presents a fourquadrant matrix (research-based, research-led, research-tutored, and researchoriented) which describes the research-teaching nexus and provides a useful framework and taxonomy for the variety of research activities that may be found within the curriculum. This study will focus on undergraduate research in the form of the senior science project, which-being student focused and emphasizing research processes and problem solving -is clearly research-based within the Healey matrix. Most bachelor degree programs in the sciences will have some sort of senior project (i.e., research project, design project, undergraduate thesis) that is used as a capstone course. By doing the project, students draw on experience and knowledge gained from earlier foundational courses and demonstrate their ability to pull it all together while creating or discovering something new. In addition to the learning benefits alluded to earlier, it also gives students a practical glimpse of what research work is about to make decisions around career direction and allows the institution to assess learning outcomes at the program level.

The delivery of undergraduate research programs (URPs) in the sciences presents additional challenges compared with the on-campus environment, where students typically work in university laboratory facilities, on research projects directed by faculty members. For distance learners, access to university research facilities is generally very inconvenient. Approaches to the distance delivery of URPs include (1) limiting the

${ }^{1}$ Sciences refers to all science-related disciplines including engineering and allied health disciplines. 
research project to a literature search, (2) having the student access and work up raw data already collected from publically available databases, and (3) offering a limited number of pre-canned projects that involve independent field work or coming into a supervised laboratory. One interesting example is the environmental sciences program at the Open University (Netherlands), where the project interface is completely online. Four-student project teams are commissioned by external clients to provide consulting products to gain real working experience and do it entirely at a distance (Ivens, De Kraker, Bitter, \& Lansu, 2007). While many of these approaches deal with the distance problem, they do not offer the same degree of freedom or the same research-learning environment for all science disciplines that the on-campus students enjoy.

This paper presents the Athabasca University (AU) model for undergraduate research across a range of science disciplines in the form of senior project courses, which is both unique and addresses many of the challenges in accomplishing this successfully at a distance. It also presents the results of an initial study into the effectiveness of these project courses, in terms of outcomes for students. The study includes analysis of student demographics and performance data, and surveys of students, faculty members, and external supervisors, examining the outcomes of these project courses for each group. This is one of the first research studies to investigate the problem of how distance learners can participate in undergraduate research programs.

\section{Description of the AU Project Courses}

The project courses in the Faculty of Science and Technology are open research-based senior undergraduate courses that act primarily as a capstone for the Bachelor of Science degree. They are available in a range of disciplines including astronomy and astrophysics, biology, chemistry, computing and information systems, environmental science, mathematics, nutrition, geography, geology, physics, and science. These courses are student-initiated (project proposal) and are based on a contracted-study arrangement (learning contract) worked out between an individual student, an approved project supervisor, and Athabasca University. Each discipline has two 3-credit (one term) project courses available (e.g., in chemistry there is CHEM495 and CHEM 496), which can be used by the student as two unrelated projects or used together as continuous research work in one area spanning two terms (one year) for 6 credits. $^{2}$

To obtain approval to enrol in the course the student submits a "project proposal," which is essentially a two-page form sent out by the course professor. Information required on the form includes student contact details, background and educational goals, relevant courses already completed, topic or specific problem to be solved, methods to be used, materials to be used, possible project supervisor, expertise and credentials of the proposed supervisor, and expected start date of the project. The

\footnotetext{
${ }^{2}$ A four-year BSc consists of 120 credits.
} 
identification and selection of an appropriate local project supervisor is very important, especially in disciplines where close direction is needed in the laboratory or field. These supervisors can be professors at other universities or experienced researchers in government or industry. In some cases, students will choose a supervisor from work and also incorporate their jobs in their learning activities.

The project may involve any combination of library, field, and laboratory work, as agreed to by the student and the project supervisor in a "learning contract" between the student and Athabasca University. The learning contract states what is to be done in the project, how and when it will be done, how it will be evaluated, and how many credits will be awarded. Not only does this individualize and personalize the project allowing students to learn using their own learning styles, and work at their own rates, it also serves to focus that work by setting clear expectations and mitigates miscommunications.

\section{Methodology and Results}

This study consists of two major components meant to complement one another. First, student demographics and performance data (e.g., enrollments, pass/ fail rates, average grades, etc.) was retrieved and analyzed. Data came from 155 students who had registered in 495/496 project courses in the previous five years. Statistical tests (student's T-test and Pearson correlation) were performed using Microsoft Excel functions.

Second, a selection of students, local supervisors, and professors/coordinators were surveyed or interviewed to provide more in-depth qualitative information and personal perspectives. The methodology and data handling were approved by the AU Research Ethics Board. The surveys were voluntary so respondents were self-selecting. The specific survey and interview questions employed are attached as supplementary material. Sixty-five students, who had completed a 495/496 course and for which valid email addresses were available, were invited by email to complete the anonymous online student survey. Thirty-one students completed the survey, giving a 48\% response rate. Eleven local supervisors were recruited randomly and interviewed by phone. The entire group of professors/ coordinators for 495/496 courses ( $n=9$ ), not including one of the authors (Shaw), were interviewed by phone.

\section{Student Demographics and Performance}

The course statistics show that there is no real difference in student performance with respect to gender. The summary shown in Table 1 indicates both average grade and distribution between pass, fail, and nonstart students is very similar between male and female students. There are a considerable number of students (29\%) who are completely 
inactive and do not complete the course. They have been designated as "nonstart" students.

Table 1

Summary of Student Performance by Gender

\begin{tabular}{|c|c|c|c|c|c|c|}
\hline \multirow{3}{*}{ Average grade (\%)* } & \multicolumn{2}{|c|}{ Female } & \multicolumn{2}{|c|}{ Male } & \multicolumn{2}{|c|}{ Total } \\
\hline & \multicolumn{2}{|c|}{84.4} & \multicolumn{2}{|c|}{83.5} & \multicolumn{2}{|c|}{84.0} \\
\hline & $\mathrm{N}$ & $\%$ & $\mathrm{~N}$ & $\%$ & $\mathrm{~N}$ & $\%$ \\
\hline Pass & 43 & 64.2 & 56 & 63.6 & 99 & 63.9 \\
\hline Fail & 5 & 7.5 & 6 & 6.8 & 11 & 7.1 \\
\hline Nonstarts $^{\dagger}$ & 19 & 28.4 & 26 & 29.5 & 45 & 29.0 \\
\hline Total & 67 & 100 & 88 & 100 & 155 & 100 \\
\hline
\end{tabular}

*Average grades between female and male is statistically insignificant $(p=0.64)$

† Nonstarts are defined as registered students who show no activity in the course.

The science project students are about 37 years old on average. There is no correlation between grade achieved and age $(\mathrm{R}=0.03)$. The average student age in various performance categories and by gender was examined (Table 2). Males appear slightly older than females (especially in the pass and fail categories), but are statistically the same age ( $p>0.05)$. Among the categories themselves the only significant difference in average age is between the pass (39.1y) and nonstart (33.5y) students.

Table 2

Summary of Student Age by Performance

\begin{tabular}{|l|l|l|l|l|}
\hline & \multicolumn{2}{|l|}{ Age $(\mathrm{y})$} & \\
\hline & Average* & Female & Male & $\mathrm{p}$ \\
\hline Pass & 39.1 & 37.2 & 40.5 & 0.08 \\
\hline Fail & 35.1 & 28.2 & 40.8 & 0.07 \\
\hline Nonstarts & 33.5 & 33.6 & 33.5 & 0.95 \\
\hline Total & 37.2 & 35.5 & 38.4 & 0.06 \\
\hline
\end{tabular}

*The only statistical difference is between the average age of students that pass and who are nonstarts $(\mathrm{p}=0.0013)$.

A review of individual disciplines shows the pass rate to vary from 43 to $74 \%$ (Figure 1). While there also appears to be a variation in grades (53-87\%) between disciplines, they are all statistically the same. The geographic distribution of students is shown in Figure 2. Students were located across Canada, with less than $1 \%$ located outside of Canada. The majority of students were located in Alberta, the province in which AU is located. 


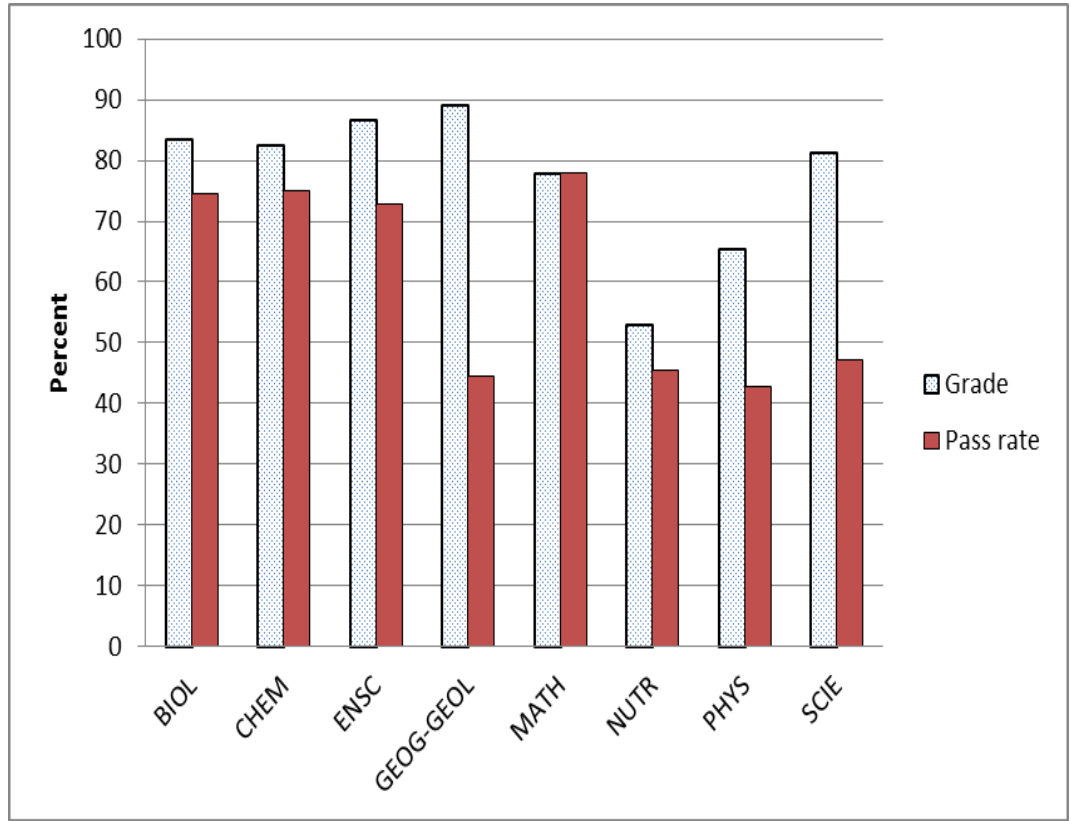

Figure 1. Average grades and pass rates by discipline. There is no statistical difference in average grades between disciplines.

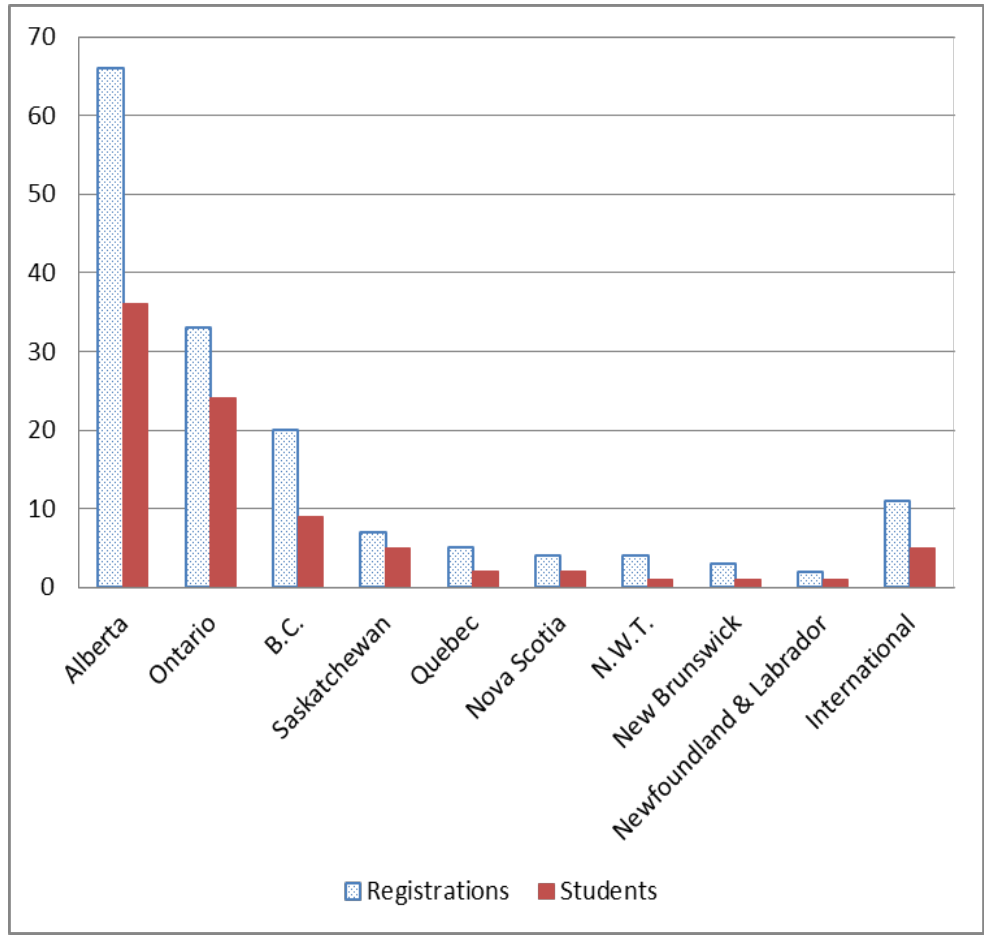

Figure 2. Geographic distribution of registrations and students. The number of students is always lower than the number of registrations because some students undertake multiple projects. 


\section{Student Perspective}

The student survey indicated that the overall project course experience was positive for students with $90 \%$ stating that they valued it. The majority were satisfied or very satisfied with the local supervisor (81\%) and the course coordinator (95\%). Furthermore, 85\% reported the experience increased their interest in research and 79\% were more likely to pursue graduate or additional certification. In probing students about what abilities and skills they developed as a result of their project experience they affirmed growth in areas suggested by the survey such as literature searching skills (48\%), laboratory skills (23\%), learning how research is conducted (42\%), communication skills (45\%), and some respondents (32\%) also suggested other areas of development like data analysis and statistics, writing, field skills, and Research Ethics Board application skills. In addition to earning credit students noted that the project course helped advance their career in several ways including getting a summer job (in one case an internship with the Smithsonian Institute), helping with medical school and graduate school acceptance, obtaining professional certification, and acquiring faster promotion at work. A substantive number of students (35\%) reported they needed more than the six-month contract time allotted for the course. The biggest positives noted by students of their experience included being introduced to research, the opportunity to do "real research," the great flexibility around location, time spent and research topic, and the opportunity to discover future directions for their own education. The students also were critical of several areas including clarity of expectations from the professor and the process, lack of feedback during the project, developing the initial proposal, and lack of face-to-face discussion with the professor.

\section{Local Supervisor Perspective}

Of the eleven interviewed, each supervised only one AU student. However, 6 out of 11 had experience with students at this level outside of AU. They noted that AU students are more motivated, more intense, and come with more experience and higher skill sets. In all cases, supervisors were approached by someone they already knew with doing a project. All would supervise another student (given the specific details of the specific project and if they had time) and cited several personal benefits to being a supervisor including following their own professional curiosity, getting academic supervising experience, obtaining insight into a new technique or area of research, helping their unit or department through staff development, and gaining a better relationship with the student. Collectively there was a solid understanding around the purpose of an undergraduate research project.

Not only did everyone agree and affirm suggested aims in the survey (such as introducing the student to research, providing an opportunity for students to use their cumulative knowledge, developing cognitive abilities and independent thinking) they also added several other goals including experience for graduate school, excellent capstone and opportunity to "bring it all together," improving scientific writing 
(organizing and structuring reports), developing self-leadership, exposure to research tools, getting real world experience, and moving from passive to active learning. All stated that their student improved as a result of the project course and acquired many of the skills noted above. ${ }^{3}$ The biggest positives mentioned by local supervisors were around the flexibility and openness of the course structure, the opportunity to mentor, gaining experience as an academic supervisor, and seeing the student grow. Criticisms of the course experience included concerns around grading and marking, logistical uncertainty around what to do or what was expected, and the low interaction and communication with the university and the course professor.

\section{Professor Perspective}

Compared to local supervisors, the professors and coordinators who oversee the project courses reported slightly different views on the purpose of undergraduate research project courses. While 5 out of 9 explicitly agreed with all of the suggested aims in the survey, the other four individuals strongly emphasized that the principal purpose of undergraduate research courses is to introduce students to research. They spoke of the importance of learning the process of research: formulating a research problem, designing the experiment, and responding to expected and unexpected data. For example, one professor described how researchers must adapt and modify their experiments based on results: "The project course allows students to make decisions based on results." Several professors made similar comments about how the undergraduate research experience was meant to give students the ability to deal with uncertainty and unexpected results.

Professors uniformly responded that they benefit from undergraduate projects courses by furthering their own research programs. Two coordinators, who do not have research programs, reported intellectual stimulation and networking as benefits. Professors saw no personal benefit was gained from having students work with external supervisors. Comments revealed that several professors make an effort to design research projects that can be completed at a distance, that are part of their own research programs. These projects usually involved computer analysis of data that can be done on the student's desktop computer at home.

Professors and coordinators noted that, compared to residential universities, research students operating at a distance are disadvantaged by the lack of contact with academics and student peers. One professor stated that at a residential university, "...the student is working in the same environment and they have better contact with students who can share similar experiences. It's easier for students to learn from the other students. The isolation places limitations on the student." On the other hand, two professors noted that $\mathrm{AU}$ is well equipped to communicate with students who are at a distance, for example through web video conferencing.

\footnotetext{
${ }^{3}$ One was supervising a nonstart student.
} 


\section{Discussion}

The student survey results in this study are consistent with other literature that shows students reporting improved skills and abilities after participation in undergraduate research programs (URPs). For example, alumni who experienced undergraduate research experienced a number of benefits compared to those who had no undergraduate research experience (Bauer \& Bennett, 2003). Benefits included improved skills and abilities, such as analyzing literature, speaking effectively, and acting as a leader. Participation in graduate studies has been shown to be significantly higher for students who have participated in URPs (Bauer \& Bennett, 2003; Hathaway, Nagda, \& Gregerman, 2002). In a study of undergraduate wildlife students, those students who participated in a URP had a higher GPA, graduated sooner, and obtained employment in their area of study sooner compared to the control group (Kinkel \& Henke, 2006). The following quote from a BSc graduate, who took several 495/496 courses, is illustrative of the impact these courses can have on a student's education and career:

After so many years I have finally achieved one of my most sought after life goals. My favourites were the chemistry and science projects courses... I was able to develop real products at work (oilfield service company chemist) and get course credit for them. This was the best training for a career in the field. (Brian O'Neil BSc, Athabasca University Annual Report 2004-2005)

The benefits of URPs to faculty members have not been studied as much as the benefits to students. One case study reported how undergraduate research could be integrated with the mentorship of junior faculty members (Thomas \& Gillespie, 2008). However, there is evidence that faculty are not directly rewarded for supervising or mentoring undergraduate research students. The most important reward for faculty is getting research done, and undergraduate research students can contribute to that (Merkel, 2001). Indeed, in our study, all of the research faculty members stated that they benefit from the project courses by furthering their own research. Interviewed faculty members noted that there is no direct reward for them to coordinate undergraduate research when it is taking place at some other institution or workplace, and not contributing to their own research program. Further rewards and recognition for URP supervision and mentoring would likely improve the quality of the student experience and expand opportunities for students.

At most large research universities, undergraduate research opportunities are limited by student-faculty ratio (Merkel, 2001). That is, there is a limit to the number of students who can be supervised individually by a single faculty member. One suggestion is to look to external institutions for other research supervisors (Merkel, 2001). This approach has been used in a master's level chemistry program, where students complete 
research that is compatible with laboratories in their workplace (Kellogg, 2011). The 495/ 496 course model, in which the location of supervisors and research facilities is not restricted, is significantly more scalable than what is possible when the undergraduate research is only possible in on-campus laboratories, and supervised by faculty. The scalability may be hampered by the lack of obvious rewards for faculty, as discussed above.

The course pass rate for project courses is $64 \%$, which is comparable to pass rates for undergraduate independent study courses at open universities of 55-60\% (Powell, 2009). Nonstart students represent $29 \%$ of the total enrolments in these project courses. This considerable number suggests that administrative systems are not effective in ensuring communication with new students or in connecting them to the faculty members who coordinate the 495/496 project courses. This seems to be confirmed by student comments about the lack of clarity of expectations and the process of starting a project.

The desire for more effective communication with faculty members was expressed by both external supervisors and the project students themselves. This was the most common criticism of the way 495/ 496 courses were operated. The 495/ 496 courses are administered almost entirely by the faculty. Each project is unique, and the students start and finish their projects at different times of the year. Over the time period of this study, each external supervisor only supervised one student. Thus, the 495/ 496 courses can be considered to be completely customized to each student. Due to the lack of any common features among projects, there is an inherent inefficiency in operating an administrative system that ensures each student and external supervisor are contacted at regular intervals. It is also challenging for faculty to keep track of, and this is a faculty workload issue. This is a very different situation from URPs at face-to-face institutions with semesters. In those URPs, students work on their individual projects as a cohort, with identical completion deadlines - usually the end of the academic year. Further, a faculty member or committee is responsible for coordinating and assessing student projects, and this is a major part of their workload. In the 495/496 courses, it is clear that more frequent contact and feedback is desired by students and external supervisors. As this is the most frequently reported opportunity for improvement, it will be important to examine ways to improve the level of contact. These criticisms underline the importance of faculty involvement in URPs, and confirm the findings of other studies (Hunter, Laurson, \& Seymour, 2007; Russell, Hancock, \& McCullough, 2007) that show that faculty mentors play a major role in facilitating positive outcomes for students.

Social constructivist learning theories can be applied to URPs in science (Hunter, Laurson, \& Seymour, 2007). A URP can be seen as an apprenticeship in research, in which the student engages in hands-on research with a mentor (i.e., research supervisor). Students and mentors collaborate together on research, and in the process students learn how research is conducted. The collaboration is inherently student- 
centred, and occurs in a 'situated' context. There is an opportunity for further research into the interactions between research students and their mentors, in the unique situation of a distance-delivered URP.

\section{Conclusions}

Undergraduate research courses are a vital part of any BSc program, but its appropriate integration can be challenging. This is much more so at universities offering courses online and at a distance. Our surveys revealed some areas for improvement in the AU model including improving communications with students and external supervisors and providing incentives or recognition to faculty to coordinate research projects with those external supervisors.

However, this current model of science project courses is unique in providing accessible, individualized undergraduate research opportunities that

1. can incorporate real research activities (including supervised work) that can be carried out without coming on campus;

2. is very scalable because external supervisors are employed; and

3. allows students to work on a research project that is tailored to their own interests.

The key feature at the heart of the AU model is the three-way learning contract that not only allows for variety and tailoring of the research topic, but also the activities and assessment of the learner. It serves as the primary communication conduit and acts as the vehicle to both project proposal and project management. Student outcomes are largely positive in terms of developing new abilities, and furthering their educational and career ambitions.

\section{Acknowledgements}

Office of Institutional Studies for supplying student performance data. 


\section{References}

Bauer, K. W., \& Bennett, J . S. (2003). Alumni perceptions used to assess undergraduate research experience. The J ournal of Higher Education, 74(2), 210-230.

Boyer Commission on Educating Undergraduates in the Research University, S.S. Kenney (chair) (1998). Reinventing undergraduate education: A blueprint for America's research universities. State University of New York-Stony Brook.

Healey, M. (2005). Linking research and teaching: Disciplinary spaces. In R. Barnett (Ed.), Reshaping the university: New relationships between research, scholarship and teaching (pp. 67-78). Maidenhead, UK : Magraw-Hill/Open University Press.

Hunter, A.-B., Laursen, S. L., \& Seymour, E. (2007). Becoming a scientist: The role of undergraduate research in students' cognitive, personal, and professional development. Science Education, 91(1), 36-74.

Ivens, W., De Kraker, J ., Bitter, M., \&Lansu, A. (2007). Collaborative learning in an authentic context: A virtual consultancy. Crossing boundaries. Innovative learning for sustainable development in higher education. Frankfurt am Main: VAS.

Kardash, C. M. (2000). Evaluation of undergraduate research experience: Perceptions of undergraduate interns and their faculty mentors. J ournal of Educational Psychology, 92(1), 191-201.

Kellogg, S. (2011). Distance learning: Online education. Nature, 478(7369), 417-418.

Kennepohl, D. K. (2013). Teaching science at a distance. In M. G. Moore (Ed.), Handbook of distance education (3rd ed., pp. 670-683). England: Routledge.

Kinkel, D. H., \& Henke, S. E. (2006). Impact of undergraduate research on academic performance, educational planning, and career development. J ournal of Natural Resources \& Life Sciences Education, 35(1), 194-201.

Merkel, C. A. (2001). Undergraduate research at six research universities - A pilot study for the Association of American Universities. Retrieved from http:// www.aau.edu/ workarea/ downloadasset.aspx?id=1900

Powell, R. (2009). Openness and dropout: A study of four open distance education universities. M-2009: 23rd International Council on Distance Education World Conference on Open Learning and Distance Education, Maastricht, Netherlands. Retrieved from http:// www.ou.nl/Docs/Campagnes/ICDE2009/Papers/Final_paper_262pow ell.pdf 
Russell, S. H., Hancock, M. P., \& McCullough, J . (2007). Benefits of undergraduate research experiences. Science(Washington), 316(5824), 548-549.

Seymour, E., Hunter, A. B., Laursen, S. L., \&DeAntoni, T. (2004). Establishing the benefits of research experiences for undergraduates in the sciences: First findings from a three-year study. Science Education, 88(4), 493-534.

Short, C., Healey, M., \& Romer, W. (2010). The changing awareness, experience and perception of research by undergraduates: The case of final year students at a new university, 2002-09. Learning Exchange, 1(1).

Taraban, R. M., \& Blanton, R. L. (Eds.) (2008). Creating effective undergraduate research programs in science: The transformation from student to scientist. New York, NY: Teachers College Press.

Thomas, E., \& Gillespie, D. (2008). Weaving together undergraduate research, mentoring of junior faculty, and assessment: The case of an interdisciplinary program. Innovative Higher Education, 33(1), 29-38.

\section{Athabasca University $\mathbf{A}$}

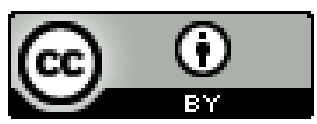

